\title{
The Application of Total Physical Response Method (TPR) in Preschool Children's English Teaching
}

\author{
Yujing Duan \\ College of Teacher Education, Zhejiang Normal University, Jinhua, Zhejiang, China
}

\begin{abstract}
This article through a four months' TPR teaching experiment among six preschool children, namely, Pre-interview, Pre-test, TPR Teaching Experiment (such as "Display and Imitation", "Instructions and Action", "Situational Communication"), Post-test, and Post-interview, attempts to investigate the application and effectiveness of the TPR method in preschool children's English teaching. The experimental results show that this approach can not only help children understand the new language quickly and gain long-term memory, but also allow children to learn English happily in a "zero stress" environment. However, abstract words and sentences are difficult to express in the TPR methods. At the same time, this "teaching through lively activities" method is easily leads to classroom discipline chaos. The TPR method also requires teachers to have high professional quality and comprehensive skills, including language expression ability, sports ability, performance skills, etc. Therefore, promoting this approach in preschool English teaching also faces technical and teaching staff difficulties. This study validates some conclusions of earlier studies which can provide experience and lessons to preschool English teachers in applying TPR as well as theoretical and practical contributions to future research.
\end{abstract}

Index Terms—-Total Physical Response Method (TPR), preschool children, English teaching

\section{INTRODUCTION}

Research that meets the needs of the times is one of the criteria to test the effectiveness of research results. Therefore, it is necessary to examine the social development trend and the requirements of the times before determining the research topic. The purpose of this part is to explain the background, purpose, and significance of this study.

\section{A. Background of the Study}

With the development of society, more and more bilingual kindergartens have sprung up. Parents generally believe that they should not let their children lose at the starting line. Therefore, they think that children should learn English as soon as possible. Many teachers take a variety of teaching methods in preschool children's English teaching, such as Situational Language Teaching method, Communicative Language Teaching method, Immersion Teaching method, Total Physical Response method, and so on. However, the English teaching of preschool children is different from primary and senior middle school and it should pay special attention to the psychological and physiological development characteristics of preschool children. Nonetheless, some teachers tend to neglect the cognitive development level of children in the implementation of English teaching, which not only hinders the improvement of children's English but also causes them to lose interest in learning English. As is known to all, interest is the best teacher for children, so it is necessary to provide suitable methods for children to improve their interest in learning English.

The Total Physical Response (TPR) method was proposed by James J. Asher, a famous American psychology professor in the 1960s (Asher, 1969). He carried out a large number of experiments on children's language teaching and combined the research results of children's development, brain side theory, and second language acquisition theory. On this basis of these theories, Asher proposed a systemic reaction method before launching the Total Physical Response method. He took a large number of empirical studies of learning a second language, the result proved that the TPR method was feasible for both adults and children in obtaining the second language (Asher, 1972). According to Asher's thoughts, once a foundation in listening comprehension has been established, the development of speech would be naturally occurring without any efforts (cited in Harrasi, 2014, p. 36). TPR followed the learner's natural process of language learning, which made learning easier and more effective by not forcing students to speak in a target language they are not yet familiar with (Asher, 1981; cited in Harrasi, 2014, p. 36). Krashen and Terrell have promoted TPR as a way of inputting language knowledge to beginners through involving in realistic, meaningful language activities (cited in Zhong, 2002, p.102).

As the superiority of TPR has been proved, more and more Chinese researchers are paying attention to this field. Yu Zhenyou has written an article titled "Asher Second Language Acquisition View and TPR Teaching Methods", which explored the characteristics and advantages of TPR teaching. In the acquisition of a second language, he summarized 
that the second language acquisition strategy was an active action response in essence (Yu, 1999). Liu Ning and Sha Jingxiang discussed the application of the TPR method in children's English acquisition in China. They believed that the TPR method conformed to the physical and psychological characteristics of children (Liu Ning, Sha Jingxiang, 2004). Wang li proposed that the TPR method was a foreign language teaching method suitable for children (Wang, 2008). Xie Rong tried to investigate the effectiveness of TPR for young learners through the case study of two teachers, and his observations showed that TPR technology is a good method based on games, role-playing, and body movements. The study also found that traditional teaching methods face challenges to TPR in practice (Xie, 2021).

However, Chinese researchers now focus on the application of the TPR method teaching method in primary school English teaching in China and Chinese teaching in foreign countries (including the United States, New Zealand, Italy, South Korea, etc.). There is little research on the field of English teaching for preschool children. So, it is very necessary to study the application of the TPR method in preschool children's teaching field from the present situation of English teaching in preschool children and the superiority of the TPR method.

\section{B. Purpose and Significance of the Study}

"Interest is the best teacher, and playing is the nature of every kid". This sentence indicates that if we want to make the kids learn English well, we must get them interested in English first, and then let them learn English in a relaxing atmosphere. From the view of psychology, the attention that children paid is called "involuntary attention" and the involuntary attention is not controlled by the ideology. That is to say, children only pay attention to things, which they are interested in. So it becomes very important for us to treat interest as the top priority. The Total Physical Response (TPR) method is based on children's psychological and psychological characteristics (Asher, 1981). It can capture children's attention and enhance their learning experience. Hence, it can be seen from the characteristics of TPR that this method is in line with the characteristics of preschool children.

However, just like McKay states that the teaching of young learners is different from adults (McKay, 2012). When it is used in English teaching for preschool children, will the features of the TPR method appear? Can teachers help a child understand a new language quickly by speaking and acting? Can children gain long-term memory when body movement and language are combined? Can the TPR method allow children to learn English under "zero pressure"? Is TPR the most popular method of Teaching English to preschool children? What difficulties do teachers face when using TPR? How to solve these difficulties? The above questions are not only the author's doubts but also her research purposes. The author hopes this rigorous experiment will answer these questions.

The significance of this study includes both theoretical and practical aspects. In terms of theory, it can enrich the theoretical depth of the TPR method. At the same time, it can provide a more scientific and effective theoretical basis for preschool children's English teaching. In terms of practice, this study can test the applicability of the TPR method for the English teaching of preschool children and find effective methods for English teaching of preschool children. The realization of these research significance still depends on the rigorous experimental operation. Therefore, the author attaches great importance to the effectiveness and availability of this research.

\section{GENeral INTRODUCTION ON TPR Method}

To gain a more comprehensive and accurate understanding of the Total Physical Response method, the author has combed and summarized the research of relevant the TPR method. This part mainly introduces the definition of the TPR method, theoretical basis. In essence, this part of the work is called "literature review" in China. Researchers in academia think this part of the work is important and necessary.

\section{A. Origin and Insights of TPR Method}

The Total Physical Response (TPR) method also was named a "Complete Repercussion", which was proposed by James J. Asher in the 1960s who was famous for American psychology. In the study of children's natural language development, he combined the results of the study of children's first language acquisition by Thompson and Gesell in the 1930s and hypothesized that there was a physiological mechanism in the human brain to acquire any natural language in the world. He proposed adults learn languages like children through body movement. To test this propose professor Asher designed and launched 40 experiments in 1969. He came to a few conclusions after observing and analyzing the TPR method in another language teaching. He pointed out "no matter how long the language was, or how long it was after training (one to two weeks), the TPR method could produce a quick understanding (Asher, 1969, p.259)".

In addition, Asher tried to pinpoint the reason for the rapid understanding and high memory rate of the TPR method. He ruled out four factors that might affect the effect of systemic reaction: location, confluence, clues, sequence. Through data analysis, he concluded that the body movements of learners were the most important factor (Asher, 1964). After a series of persistent experiments, Asher also found that adults could learn a second language as a child. This is contrary to popular belief that children are always better than adults in second language acquisition. Asher believed that children had a talent for language acquisition after a great deal of observation and adult language acquisition. In contrast, adults learned a second language in a non-game environment and their body movements and language were separate when they were learning a second language. Later Asher proved that adults could even surpass the children when they 
had the opportunity to learn the language through listening and moving (Asher, 1974).

Then, what is the relationship between teachers and students when TPR is applied to teaching activities? Asher pointed out that teaching activities were like a stage performance where students were actors and teachers were directors. It emphasized that teachers played an important guiding role in the overall teaching activities. More importantly, it also encouraged children to experience and participate in activities (Kunihira \& Asher, 2009). It's worth mentioning that H. E Palmer pointed out 60 years ago that "instruction drill" was best suited to complete beginners. He went so far as to claim: "In the early stages of English teaching, the success of the teaching method cannot be achieved without providing students with plenty of opportunities to participate in activities" (cited in Zhong, 2002, p.102).

\section{B. Theoretical Foundation of TPR Method}

A great deal of scientific research suggested that the left and right hemispheres of the human brain were responsible for different tasks. American physiologist Roger Wolcott Sperry conducted the Lacerate brain, this was verified that the left brain could express itself by speaking. Based on these theories, Asher proposed a bold hypopaper that children interpreted and understood language through the right brain. People received and understood language by observing the differences between adult behavior and verbal behavior (Vicory \& Asher, 1966). Therefore, learning a second language was a process of using the right brain to establish a link between a second language and physical activity. In fact, many experiments have shown that the speech and behavior of the parents were the favorable stimuli when the infant learns language, and even if the left side of the baby's brain was unable to speak the first time, this effect continues until the left side of the baby's brain became capable of speaking. Therefore, Asher believed that the best way was to use the right brain to understand the unfamiliar second language. One side of the brain works while the other was stimulated. This greatly improved the efficiency of learning. the learning process became slow when the language information was only entered into the brain from the left hemisphere. So, the TPR method advocates that the learners should first learn a lot of information before they begin to speak and that the coordination of gestures and body movements is very important (Asher, 2009).

In addition, the theoretical basis of the TPR method includes psychology. There are two main aspects to it in psychology. On the one hand, the body reaction method absorbs the theory of "memory trace" in psychology (Bing Ni et al., 2017). The theory holds that the more profound the process of memory, the easier it is to associate and recall. Due to children's language is an imperative sentence many children generally dependent on physical reactions. Children are easy to remember when these movements are linked to language. On the other hand, the TPR method also absorbs the viewpoint of humanistic psychology. This theory claims that emotional factors play an important role in language learning. It is suggested that the teaching method with game activities can reduce students' psychological burden and improve learning efficiency (Charlotte, 1971).

Finally, the TPR method is based on linguistic theory. When Asher created the TPR method he did not directly discuss the language theory basis of the TPR method, but from the perspective of the form and practice of the classroom organization of the TPR method, which was related to the concept of language. This method embodied the verb as the core content of the language, especially the verb in the imperative sentence and the language learning. When learning a language, learners needed action participation and a relaxed and happy atmosphere, which was the key factor for them to have a good learning experience (Carless, 2003). Nowadays, most researchers and practitioners who agreed with the TPR method argued that the atmosphere of most foreign language classes was too intense and hoped to create a foreign language teaching method to reduce the pressure of learners and awareness of self-defense in the classroom.

\section{Characteristics of Preschool ChildRen}

Preschool children mainly refer to children between the ages of 3 and 6 Children in this stage have obvious and unique characteristics including psychology, cognition, and language. Researchers suggest that teachers should follow their characteristics in the development of preschool children's English teaching.

\section{A. Psychological Characteristics of Preschool Children}

Generally speaking, the psychological characteristics of preschool children mainly have three aspects. Firstly, preschoolers tend to imitate others because they have poor independence, and they tend to imitate others. They are very observant and tend to mimic the movements and words of those around them (Rukavishnikova, 2016). Therefore, we should pay attention to our own words and deeds and set a good example for children. Secondly, their unintentional attention is dominant. Unintentional attention is also called "involuntary attention". It does neither require a predetermined purpose nor subjective efforts. Children have a higher level of unintentional attention in the preschool stage. Anything that is in line with their interests or experience will attract their unintentional attention. Children of all ages have different physiological and psychological development, their unintentional attention also shows different characteristics. In the classroom, the three-year-old child can hold their attention from 3 to 5 minutes, four years old may last for 5 to 10 minutes, the 5-year-old for about 10 to 15 minutes, five and six is likely to remain at the age of 20 to 25 minutes (Savage et al., 2006). Finally, intentional attention begins to develop. Intentional attention refers to a proactive form of attention that requires willpower control, which is subject to the automatic regulation and control of human consciousness. Intentional attention depends on some factors. For example, clear objectives and tasks of 
activities (Hilary \& Vanessa, 2018).

Therefore, in the English teaching of preschool children, to ensure that children actively participate in activities, teachers should fully grasp the psychological characteristics and physiological development of children. They should make full use of children's unintentional attention, and at the same time, teachers should try to cultivate children's intentional attention.

\section{B. Cognitive Development of Preschool Children}

Jean Piaget divided the cognitive development process of children into four stages, which were: Sensor Motor Stage (Birth to 2 Years), Pre-operational Stage (2 to 7 Years), Concrete-Operational Stage ( 7 to 11 Years), Formal-Operational Stage (11-12 Years and Beyond). Each stage was not the sum of some isolated behavior patterns but the unity of the whole. Each stage has its main behavioral pattern, which marked the behavioral characteristics of this stage. The previous stage of behavior was always integrated into the next stage, each of which was derived from the previous stage of the structure, the former was the preparation of the latter, and was replaced by the latter. The stage of child cognition has some degree of overlap. The age at all levels of cognitive development could be delayed in advance because of individual intelligence, motivation, exercise, and education impact, as well as differences in the social environment. But the order of the stage was the same, and couldn't be reversed (Piaget, 2013). Preschool children are in the Pre-operational Stage. In this stage, children begin to emerge from concrete actions due to the appearance of symbolic functions. They are different from children at the sensory-motor stage. In this stage, they begin to internalize behavior and could think before moving an object. However, they have not yet formed the psychological structure, they could only operate at the level of representation. Jean Piaget believed that children at this stage could use language and form mental representations and could use symbols to reproduce the external world in their minds. But the children of this period couldn't leave things to use language and symbols. In terms of cognition, children were very different from adults in learning foreign languages. That is, the lower a child's level of cognitive development, the more they need to pay special attention to the meaning of language. Because they don't have the flexibility to think abstractly, they can only see the immediate concrete (Corsaro, 1981).

The above cognitive development features of children provide important references for teachers in English teaching. In English teaching, teachers should not provide children with abstract concepts and original things but should provide more concrete, intuitive teaching tools. At the same time, teachers should be more careful about children's activities to help them translate their language learning needs into physical responses. Finally, children should take an active part in English learning activities. In conclusion, the learning process of children should be one in which they can actively participate. The purpose of education is not only to let children acquire knowledge but also to help them improve their interest in learning.

\section{Linguistic Features of Preschool Children}

The linguistic features of children mainly include speech function. On one hand, in terms of pronunciation, Children's pronunciation ability depends on the maturity of their vocal organs and the ability of the brain to regulate their vocal organs. Children's pronunciation skills are improved very quickly, especially between the ages of 3 and 4 . Under the correct education, 4-year-old children can master the entire pronunciation of the nation. They stay in the critical period and sensitive period for children when they are 3-6 years old to learn a language (Visser-Bochane et al., 2020). It is pointed out that if people start to learn a second language in the teenage stage, they will have difficulty learning pure pronunciation. On the other hand, preschool children already have the initiative in using verbal communication skills and the ability to regulate speech in terms of speech function. With the growth of children's age, children's language expression ability will be improved continuously. Meanwhile, Online fairy tale activities and picture fairy tale activities can improve children's language comprehension and expression ability (Hyun et al., 2006). Children aged five to six can speak more, but their level of expression is still at a lower level. In general, the characteristics of language development of preschool children are as follows:

a. From the language of dialogue to monologue language.

b. It gradually develops from situational language to coherent language.

c. They can use nonverbal information such as facial expressions, gestures, and tone of voice to facilitate communication.

d. Being more and more sensitive to the social situation factors of effective communication, I can use a variety of conversational skills to euphemistically express my requirements.

e. Be able to adjust your speech according to the characteristics of the listener.

In preschool children's English teaching, they need to take into consideration of the linguistic features of preschool children when they are in English teaching. Cameron, L suggested that priority should be given to the listening and speaking practice in English teaching (Cameron, 2001). In other words, the English teaching of preschool children is should be aimed at simple daily communication and give priority to listening and speaking in English learning.

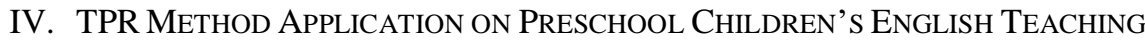

The purpose of this part is to introduce the research design and the process of a teaching experiment, including the 
following five parts: Research Aims and Questions, Research method, Participants, Curricular Contents, Research Plan. In addition, the research plan was divided into five steps: Pre-interview, Pre-test, TPR Teaching Experiment, Post-test, and Post-interview. To ensure the reliability and validity of the research, the author designed a systematic and scientific research link.

\section{A. Research Aims and Questions}

To inquire into the feasibility of the TPR method in the teaching practice of children's English teaching and learning, the author did some empirical researches and collected some data through interviews, Pre-test, teaching experiment, and Post-test. By doing these measures, the author hopes to solve the following research questions.

RQ 1: To investigate the application of the Total Physical Response method in English teaching for preschool children.

RQ 2: To what degree does the Total Physical Response method affect children?

RQ 3: How does the Total Physical Response method help children keep a better memory of the knowledge they have learned?

RQ 4: How does the Total Physical Response method improve children's interests in learning English?

RQ 5: What are the shortcomings of the Total Physical Response method in teaching practice and what should teachers pay attention to in using this method?

\section{B. Research Method}

After a long process of teaching, the author used the quantitative research method and empirical research method to carry out this research. The author investigated the application of the TPR method in preschool teaching through interviews and used the method of quantitative research to judge the feasibility of the TPR method. At the same time, the author designed and implemented English teaching according to the principle of the TPR method. The effectiveness of the TPR method was analyzed by observing and comparing children's performance. This teaching experiment lasted for four months from September 2019 to December 2019. The author first selected six preschoolers. The author explained the study to their parents. Fortunately, they all agreed that their children participated in the study. Six children were then divided into experimental groups. The experimental group was taught by the TPR method. From September 2019 to December 2019, they received the TPR English teaching training twice a week (one and a half hours each time), mainly on Saturday and Sunday, because they went to school from Monday to Friday. The author designed and conducted the first interview and test in early September 2019, just as the children were about to start school, and the second in late December 2019, just before they were on vacation.

\section{Participants}

This study followed the general process of purposeful sampling. Patton believed that purpose sampling was effective when researchers sought participants who provided valuable in-depth information for the study (Patton, 1990). To understand the application and effectiveness of the TPR method in preschool children's English teaching, a four months teaching experiment was carried out among 6 preschool children in a classroom (including two boys and four girls) at an English training institution in Luoyang, Henan Province.

For all the local English training institutions, the author conducted a field survey on the number, location, operation, personnel, students, courses, teaching, and other aspects of these institutions. In the end, the author chose to work with this organization because it met all the requirements. After that, the author communicated with the head of the institution to ensure that they have a comprehensive understanding of the study. Finally, after obtaining their consent, the author sent them a written consent and signed it for confirmation.

In the case of the study participants, it was mainly six children in a class at a partner institution. After investigation, the author found that all six children were in the preliminary stage of English learning. To ensure the smooth development of the study, the author introduced the purpose, time, and confidential information of the interviews to the teachers and parents of these children in advance, and conducted interviews and tests after getting their oral consent. In the end, the children's teaching experiment was all approved by parents and teachers.

\section{Curricular Contents}

To ensure that children can grow up healthily and happily, the Ministry of Education of the People's Republic of China stipulated that the kindergarten curriculum cannot be based on the curriculum of primary school. Teaching the content of primary school in advance was forbidden by this department (Ministry of Education, PRC., 2012). Therefore, the author carefully selected the appropriate course content for this teaching experiment according to the regulations of the Ministry of Education of the People's Republic of China.

According to the characteristics of preschool children, the author wants to help children learning some common nouns, adjectives, verbs, and simple communicative language in this teaching arrangement. For example, some basic nouns (characters, animals, plants), adjectives (height, length, and color, etc.), verbs, and simple imperative sentences. These teaching contents come from children's lives, so they are helpful to attract children's interest and help them improve their understanding. Most researchers think that the TPR method is completely different from those teaching methods which take grammar or structure as the core element of language. The TPR method emphasizes that learning 
content should be selected according to vocabulary usage and learners' needs. Therefore, the TPR method fits the characteristics and needs of preschool children.

\section{E. Research Plan}

The study was conducted in five steps, including Pre-interview, Pre-test, TPR Teaching Experiment, Post-test, and Post-interview. The research plan was shown in the following chart. In terms of interviews, the form of semi-structured interviews was adopted, that was, the author formed a relatively complete interview outline before the interview began, but this outline could be adjusted according to the actual situation. Then asked questions according to the previous interview outline. For TPR teaching experiments, in essence, this research belongs to the Design of Experiments Single Group Pre-test and Post-test. In such an experimental study, a group of subjects was tested before the test, then the subjects were treated by the experiment, and finally, the subjects were tested after the test. The results were determined by comparing the results of the two tests before and after. Generally, this method was simple and easy to operate, but because there were only one group of subjects, some unrelated factors in the study couldn't be better controlled, such as emergencies, personal experiences, and physical and mental changes.

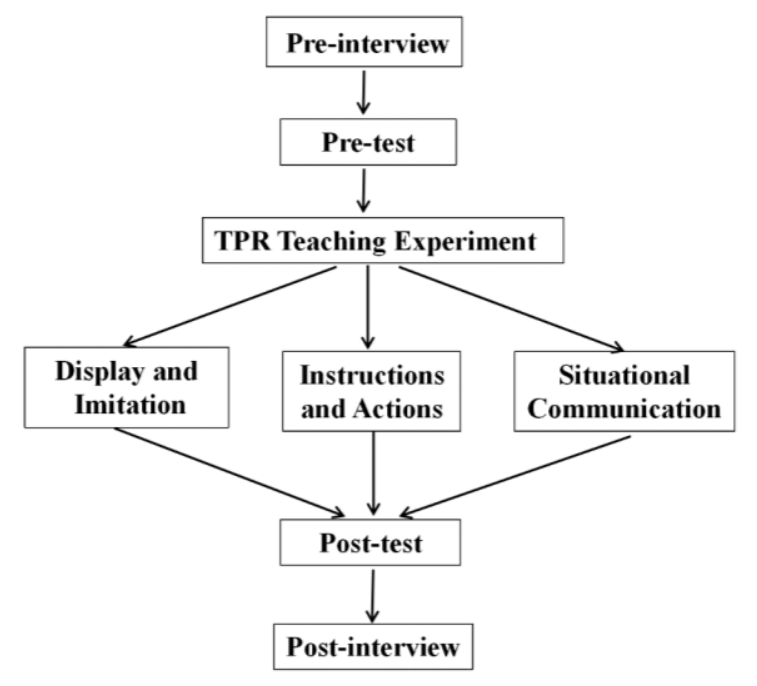

Chart 1 Flowchart of Research Proposal

\section{Pre-Interviews}

To understand the applicability of the TPR method in preschool children's English teaching, as well as the learning interests and learning styles of preschool children, the author designed in-depth interviews. The interview outline was designed before the interview. In addition to the basic information of the interviewees (six preschool children), the interview included five parts: "interest in English learning", "participation in English activities", "expectation of English learning style", "cognition of the TPR method" and "expectation of the TPR method". The questionnaire included the following questions:

a. Do you like English? Can you explain your reasons?

b. Do you often participate in English learning activities? How do you usually take part in English learning activities?

c. How do you want to learn English?

d. Do you know the TPR method?

e. Do you want the teacher to use the TPR method?

\section{Pre-Test}

To get an idea of the subjects' actual English proficiency, each of the six children took aptitude tests in turn before the study began. To prevent the subjects from being influenced by other factors, especially other children, only one child was tested at a time. To ensure the objectivity and scientifically of the test, each test was performed by the same tester (mainly the researcher himself). To ensure the reliability and validity of the experiment, these test contents were designed according to the requirements of the TPR method. The score of the test was 100, and the questions were divided into Connection (50 points), Speaking ( 25 points), and Listening ( 25 points). The listening part of the exam is to listen to some words and point out the picture that is consistent with the meaning of the word. Five points for a correct answer and a total of ten questions should be answered. Speaking part of the exam is to see the picture or model and speak the English meaning about them. Five points for a correct answer and a total of five questions should be answered. Listening includes 5 instructions "Stand up!" "Sit down!" "Point to me!" "Pick up the paper!" "Put down the paper!" The examination results are shown in Table 1. 


\section{TPR Teaching Experiment}

\section{a. Display and Imitation}

Children's learning begins with imitation. The TPR method emphasizes that teachers should play an exemplary role. At the same time, preschool children are mainly specific imagery thinking. Only when they feel and participate at the same time can they understand things. The word itself has generality, so children need to learn something related by looking, listening, touching, tasting, and so on. For example, let the children learn "what is water?" Teachers must put a bottle of water before them. Therefore, "Display and Imitation" is an important part of English teaching.

So, who will show it? Show what? Who is the show? How do the show? In this link, the author displayed the English vocabulary that needed to be studied by children through pictures, objects, or movements, such as nouns (common characters, animals, plants, and so on) adjectives (color: red, yellow, green, blue, blue, purple, black, white) verbs (stand up, sit down, picking up, putting down), and so on. This vocabulary mainly involved family members. When learning this English vocabulary of family members, the author showed the pictures of "father, mother, sister, brother, brother, grandfather and grandmother" and told six preschool children the English names. After they learned and remembered these words, the researcher organized a game__ “Tell Me, Me Guess", which was very popular with children. In the game, the children modeled the family characters, and the other children made judgments about the characters they modeled. After the game, students used the same method to learn words about animals and plants. When learning adjectives, the author collected colorful balloons. Especially the colors that children like. Before the activity began, the author introduced the children to the colors of the balloons in English and then asked the children to read the words after her. Once the children had memorized the colors, the author assigned one child to hand out balloons on command, while the others were instructed to pick up balloons of different colors. For English verbs, to make it easier for the children to learn English verbs, the author showed the English verbs while instructing the children to imitate the actions together. In learning to "stand up, sit up, pick up, put down," the author introduced the verbs in English while demonstrating the movements with their bodies. The children in the classroom mimicked the author's words and actions together. In the practice of "greeting", students learned how to express greetings in English by imitating the author's language and actions. This approach is also known as "Display and Imitation."

"Display and Imitation" is not only the quintessence of the TPR method but also a model of English teaching for children. This approach is consistent with the physical and psychological characteristics of children. It provided a relaxed learning atmosphere for children and stimulates their interest in learning a second language. In this way, students learned how to express greetings and needs in English by imitating their teacher's words and actions. As a result, the children not only enriched their life experience but also improved their English ability.

\section{b. Instructions and Actions}

Preschool children love to move. They have difficulty maintaining consistent attention. Given this, according to the teaching principles of the TPR method, children should learn English by listening and moving. By instructing and moving, they can improve their focus and learn to express themselves freely. Teachers can use a series of verbs and imperative sentences to guide children to do actions. Under the guidance of teachers, children can exercise actively and learn effectively. Asher (1977) states that TPR could build learners' confidence, when learners respond to the instructions through body movement because students feel secure and happy, do not worry about making mistakes (Celestino, 1993). In short, "Instruction and Action" is one of the most basic principles of the TPR method, which is consistent with the nature and characteristics of the child.

Such activities needed large spaces, so the author carefully designed the spaces. Before the event, the author began with daily greetings such as "stand up" and "sit down". Because preschool children have a strong competitive spirit. They like to express themselves, and they want to be appreciated and recognized by others. So the author designed a variety of forms of competitive learning activities, such as word answering, guessing mouth shape, selecting "little teacher" and so on. In these games, the children participated in activities together, and after the activities, the author presented the winners with nice little gifts. The winning child then served as a coach for the second and more rounds. This method not only improved students' interpersonal skills but also promoted their interest in learning English. For English words that represent the color, the author first looked for a nearby color, such as a yellow table. The author pointed to the yellow table and said, "Look here, it's yellow, yellow, yellow." The children learned the other colors in the same way. After many classes, the children were familiar with common plants and animals, colors plus plants, shapes plus animals, and so on. So the author developed the difficulty and complexity of the commands. For example, "colors plus plants plus action", "names plus action plus shapes plus all kinds of toys", and so on. The author handed out carnations and said, "Please pick up the red carnation and put it down", or "Please pick up and put down the dinosaur". In this way, the children remembered English words. This method has helped children expand their vocabulary.

"Instructions and Actions" is one of the characteristics of the TPR method, and it is also an important method to help preschool children to improve. On the one hand, children are at a sensitive stage of language development, because of their limited vocabulary, such activities improved their vocabulary and English listening and speaking level. On the other hand, preschool children's body organs have not yet developed, so early childhood is a period of very rapid growth and development of children. "Instructions and Actions" liberated a child's body. Children's physical 
participation is conducive to the development of their physical functions. Children developed memory, reflexes, and motor skills through "Instructions and Actions". Therefore, "Instructions and Actions" fits the characteristics of preschool children and is a very meaningful teaching method.

\section{c. Situational Communication}

Situational Communication refers to teachers and children talk to each other by imitating the same roles which they play in virtual situations. The children have a rich imagination and a talent for acting. They have an excellent ability to imitate and a strong desire to perform. Therefore, this activity is very popular with children and is also widely used in other activities in kindergartens.

When carrying out situational communication activities, the author first introduced the activity situation to the children through oral English, facial expressions, body movements, or other teaching tools. This scenario was mainly derived from the children's real life. Such as "making an introduction", "doing housework", "organizing birthday party" and so on. For example, in the study of introductions, the author instructed one child in the class to play the role of a new classmate. When the "new classmate" introduced himself, the other five students in the class took turns introducing themselves. Or, to learn how to celebrate birthdays, the author simulated a group birthday party, children listened to the song "Happy Birthday to You" and learned the birthday greeting "Happy birthday to you!", "Here's a gift for you", "Oh! How nice. Thank you!", "Let's have some birthday cake/ milk" and some grateful answers, such as "thank you", etc. In addition, the author used PowerPoint to show the children a bear family doing housework. After that, the author used the hygiene tools in the classroom and demonstrated various household chores to ask the students to express the author's actions in English. The author then created situations that encouraged the students to perform on stage. These dialogues were convenient for students to learn, and these situations were close to students' life. All in all, this method was of great help to children.

"Situational Communication" is also a performance game. This kind of play developed young children's imagination. The plot was fictional and the props were fake. To enhance the performance and the fun, they had to treat all of this as if it were real. This kind of fake activity was carried out by the participant's imagination. In addition, situational communication required children to imitate the roles, actions, and dialogues of the characters in the works. When they stood in the position of the role to perform the role, they needed to consider the feelings of the role. Therefore, this process improved children's interpersonal skills and language expression skills.

\section{Post-Test}

During the TPR teaching activities, some interesting phenomena were discovered by this experiment. These children listened attentively to the researcher's instructions and tried their best to translate the researcher's instructions into their body language. Especially after setting up the reward mechanism, students were both active and excited. Even some of them who were not normally active were more likely to participate. The students' eyes, ears, mouth, mouth, hands, and other parts of the body were active in the activity. This activity was vivid and interesting, which stimulated the interest of beginners to learn English and cultivated their good language learning. In a word, the activation process of "the Total Physical Response method" fully reflected the main role of students.

The subjects took the final text after the experiment with the TPR method. The score of the test was 100, and the questions were divided into Connection (50 points), Speaking (25 points), and Listening (25 points). In this test, a child listened to words and pointed out the pictures that were consistent with the meaning of the word. Five points for a correct answer and a total of ten questions were answered. The speaking part of the exam was to see the picture or model of the child and told the English meaning of it. Five points for a correct answer and a total of five questions were answered. Listening included 5 instructions "Stand up! Sit down!", "Point to me! Point to you", "Pick up the paper! Put down the paper!", "Please walk to the chair! Stop!", "Please walk to the table! Stop! Sit down". They got 5 when the respondents were right. The examination results are shown in Table 2.

\section{Post-Interview}

The data in the experimental study accurately and objectively reflected the research results. Based on analyzing the research results, I further inferred the influence of the experiment on the research object (including positive and negative). However, the subjects' personal feelings and internal changes (such as interest, emotion) couldn't be obtained by testing. Therefore, interviews needed to understand the above. Only in this way could I obtain more comprehensive research results on this TPR teaching experiment. After the whole teaching experiment, I interviewed the six children from the experimental group to know their opinions about the TPR classes. The children were very young but they have a certain feeling about the classes and the teaching style. The questionnaire included the following questions:

a. Do you like learning English now?

b. Do you often participate in English learning activities?

c. How do you want to learn English?

d. Do you like the TPR method?

e. Do you want the teacher to continue to use the TPR method? 
In this part, the data collected through interviews and tests, as well as observation were analyzed in detail. By examining whether the results answered the previous research question, the author examined whether the teaching experiment had achieved the purpose of the research. On the one hand, the interviewing author has understood the children's evaluation of the TPR method, the application of this method, and the challenges it faces. On the other hand, the test results have been listed in a table, which was a more intuitive representation of the results. It reduced the subjectivity of the experiment. The effectiveness of the TPR method was detected by comparing the results of pre-test and post-test subjects.

\section{A. The Result of Data Analysis of the Tests}

There were two tests in the whole research, one was conducted before the experiment, the other was conducted after the experiment. To understand children's current interests and levels of English learning, the author designed a pre-test. The children were required to be tested one by one in the same classroom. And the author gave the scores according to their performance of each part, then calculated the total scores. The scores and the specific analysis of the pretest are as follows. The examination results are shown in Table 1.

TABLE 1

EXAMINATION RESULTS OF PRE-TEST

\begin{tabular}{|l|c|c|c|c|}
\hline \multicolumn{1}{|c|}{ Test Content } & $\begin{array}{c}\text { Connection } \\
(50)\end{array}$ & $\begin{array}{c}\text { Speaking } \\
(25)\end{array}$ & $\begin{array}{c}\text { Listening } \\
(25)\end{array}$ & $\begin{array}{c}\text { Aggregate } \\
(100)\end{array}$ \\
Name & & 10 & & \\
\hline Zhang Shiyu & 20 & 10 & 10 & 40 \\
\hline Zhang Zixuan & 15 & 15 & 15 & 50 \\
\hline Liu Mengran & 20 & 15 & 10 & 45 \\
\hline Xia Zexi & 20 & 10 & 10 & 35 \\
\hline Wei Yi & 15 & 10 & 10 & 30 \\
\hline Wang Shuo & 10 & & & 35 \\
\hline
\end{tabular}

The results in table 1 showed that the total scores of six children are less than 50 . Most of them didn't understand English instructions. Some children made the right action by imitating their peers and most of them didn't know the English names of the common things in life.

To test the effectiveness of the teaching experiment, the author tested the English ability of six children after four months of teaching the experiment. By testing the results, the author learned about the children's English proficiency after the TPR method. This test was just like the pretest and the children were required to be tested one by one in the same classroom. The specific scores and analysis of the post-test are as follows. The examination results are shown in Table 2.

TABLE 2

EXAMINATION RESULTS OF POST-TEST

\begin{tabular}{|l|c|c|c|c|}
\hline Test Content & $\begin{array}{c}\text { Connection } \\
(50)\end{array}$ & $\begin{array}{c}\text { Speaking } \\
(25)\end{array}$ & $\begin{array}{c}\text { Listening } \\
(25)\end{array}$ & $\begin{array}{c}\text { Aggregate } \\
(100)\end{array}$ \\
Name & & 25 & 25 & 100 \\
\hline Zhang Shiyu & 50 & 20 & 20 & 95 \\
\hline Zhang Zixuan & 45 & 20 & 25 & 85 \\
\hline Liu Mengran & 40 & 25 & 25 & 100 \\
\hline Xia Zexi & 50 & 20 & 20 & 90 \\
\hline Wei Yi & 40 & 25 & 25 & 90 \\
\hline Wang Shuo & 45 & & & \\
\hline
\end{tabular}

The results showed that most of them were above 90 points and only one of them was below 90 points. Compared with the first test, this test showed that children's English proficiency made great progress in many aspects. It was easy to find out how much progress children have made after receiving teaching experiments.

As can be seen from the above data, the whole teaching result was very satisfactory. The advantages of the TPR method were mainly reflected in the following aspects: Firstly, this method helped children quickly understood new 
languages by speaking and moving. Secondly, children gained long-term memory when their body movements and language were combined. Finally, children learned English under "zero pressure" and stimulated their interest to study. However, the TPR method had the following problems in preschool children's English teaching. There was a limit to the vocabulary and language by using pictures, physical objects, body movements, etc. The TPR method was only applicable to preschool children in the primary stage. However, this method was difficult to apply to other areas. In addition, a large of number activities and games learners were excessively excited. So the author suggests that classroom management should be established and good classroom discipline should be maintained.

\section{B. The Result of Data Analysis of the Interviews}

To find out how the children felt and changed before and after the teaching experiment, the author interviewed six preschoolers. By comparing the results of the two interviews, it was found that there were significant changes in the attitude and evaluation of these children in English learning and the TPR method. Here are the details:

The first one was to investigate whether they were interested in English before they came to this class, six children were not interested in English. But all the children have shown that they have great interest in learning English after the teaching experiment. The second question was whether they used to take part in English learning activities often. Before the beginning of the teaching experiment, by visiting six children, it was found that only two thought they participated in English learning activities. The other four children were unwilling to participate in such activities. However, after the end of the teaching experiment, all of them participated in English learning activities. The third question was about their expectations in learning English, all children hoped that they could learn English through singing, acting, games, and so on, just like the TPR method. The four-question was about their thoughts as to the TPR method, all children thought the TPR method was very interesting, they learned English through playing instead of just following the teacher. The last question was whether the children want the teacher to keep using the TPR method, five children hoped their teacher to keep using the TPR method and two children had no idea about this question and did not give clear answers.

Above all, it could be found from the children's answers that children were satisfied with the TPR method, and they expected English teachers to continue to use this method in future teaching. In addition, their English ability has been improved in such teaching activities. As a result, the author suggests that the TPR method should be applied by more English teachers in teaching activities. However, as the saying goes, "No one is perfect". The TPR method have also some shortcomings, teachers should pay attention to these shortcomings to improve the teaching effect.

\section{CONCLUSION}

This research not only provided the background, the purpose, and significance of the study, but also introduced the Total Physical Response Method in detail including its background, definition, theoretical framework, and so on. Meanwhile, the paper presented characteristics of preschool children and common teaching methods in preschool children's English teaching. The most important thing was that the advantages and disadvantages have been found in the research process.

In summary, the Total Physical Response Method, as effective teaching, is worthy of promotion and application for preschool English teaching in the future. Firstly, the TPR method is a rich and interesting teaching form, which can not only attract the attention of children but also can improve their enthusiasm for learning a foreign language. According to Jean Piaget's theory of cognitive development of children, teachers should provide children with various sensory stimulation when they carry out activities of English teaching. The TPR method advocates that learners should link language and behavior together when they learn the language. When teachers teach verbs like walking, running, jump, etc., they can make children understand the meaning of these words by speaking and acting. Therefore, the TPR method is very suitable for children's characteristics. Secondly, the TPR method paid little attention to children's mistakes in their learning process. It can create a relaxed and happy atmosphere in the classroom, which makes it easy for children to eliminate tension. So, it is helpful to help students eliminate fear and nervousness and enable students to learn in a zero-stress environment. Finally, the TPR method provides a learning environment that is closely related to real-life so that they can learn a foreign language in a variety of activities and apply what they learned. As we all know, preschool children are at the age of 3 to 6 stages in the critical period of language development, so their parents and teacher should grasp the critical period and make full use of the advantage of TPR to promote the improvement of English ability.

However, every coin has two sides, and the TPR method is no exception. The abstract words and sentences are hard to express in the TPR method. To improve learning efficiency and learners' satisfaction, the user needs to be organically combined with other teaching methods. The TPR method requires the teacher to have high professional quality and comprehensive ability, including language expression ability, body coordination ability, artistic talent, and so on. Therefore, when teachers use the TPR method in practice, they must strengthen the training of professional skills and improve their knowledge and accomplishment. To sum up, different methods have their unique characteristics. According to the different needs of children, preschool teachers should choose a more suitable method for children, especially the Total Physical Response method.

Although many scholars have researched the TPR method in English teaching, the paper pays more attention to preschool children's English teaching. In addition, the advantages and disadvantages of the TPR method in practice are father discovered by the research, and a reasonable establishment is proposed. Although there are many limitations in 
this research, the author hopes it can make some contribution to further study.

\section{REFERENCES}

[1] Arthur C. Vicory \& James J. Asher. (1966). A simplified associative-frequency measure of meaningfulness in verbal learning. Academic Press, 5(6), PP 507-513.

[2] Al Harrasi, K. T. S. (2014). Using "total physical response" with young learners in Oman. Childhood Education, 90(1), 36-42.

[3] Buhler Charlotte. (1971). Basic theoretical concepts of humanistic psychology. American Psychologist, 26(4), PP 378-386.

[4] Bing Ni, Ruijie Wu, Tao Yu, Hongwei Zhu, Yongjie Li \& Zuxiang Liu. (2017). Role of the Hippocampus in Distinct Memory Traces: Timing of Match and Mismatch Enhancement Revealed by Intracranial Recording. Neuroscience Bulletin, 33(06), 664-674.

[5] Celestino, W. J. (1993). Total physical response: commands not control. Hispania, 76 (4), 902-903.

[6] Cameron, L. (2001). Teaching languages to young learners. Cambridge, UK: Cambridge University Press.

[7] David R Carless (2003). Factors in the implementation of task-based teaching in primary schools. System, 31(4), 485-500.

[8] Elena E. Rukavishnikova (2016). Specific Psychological Characteristics of Interpersonal Relationships in Preschool Children. Procedia - Social and Behavioral Sciences, (233), PP118-122.

[9] James J. Asher (1964). Vision and Audition in Language Learning. Perceptual and Motor Skills, 19(1), PP255-300.

[10] James J. Asher (1969). The Total Physical Response Technique of Learning. Journal of Special Education, (3), 253-262.

[11] James J. Asher (1972). Children's First Language as a Model for Second Language Learning. The Modern Language Journal, 56(3), 133-139.

[12] James J. Asher., J. A. Kusudo, and R. De La Torre. (1974). Leaning a Second Language Through Commands: The Second Field Test. The Modern Language Journal, 58(1/2), PP24-32.

[13] James J. Asher. (1981). The Total Physical Response: Theory and Practice. Annals of the New York Academy of Sciences, December Vol.379 (1), pp.324-331.

[14] James J. Asher. (2009). Evidence for "Genuine" One-Trial Learning. IRAL - International Review of Applied Linguistics in Language Teaching, 1 (1), PP 98-103.

[15] Jean Piaget. (2013). Child's Conception of the World. Abingdon: Taylor and Francis.

[16] Kim Hyun, Kim Man, Cha Hyun-hwa \& Hong Hui-kyung. (2006). The Effects of Internet Fairy Tale Activities and Picture Fairy Tale Activities on Young Children's Language Comprehension and Expression Abilities. Korea Open Association for Early Childhood Education. 11 (5), PP 251-268.

[17] Liu Ning, Sha Jingxiang. (2004). Application of TPR in Chinese Children's English Acquisition. Journal of Beijing Institute of Technology (Social Section Academic Edition), (S1),48-51.

[18] McKay. P. (2012). Assessing young language learners, UK: Cambridge University Press.

[19] Ministry of Education of the People's Republic of China. (2012). Notice of the Ministry of Education on Standardizing the Kindergarten Conservation Education to Prevent and Correct the phenomenon of "Primary Education".http://www.moe.gov.cn/src site/A06/s3327/201112/t20111228_129266.html

[20] Miller Hilary E \& Simmering Vanessa R. (2018). Children's attention to task-relevant information accounts for relations between language and spatial cognition. Journal of experimental child psychology, (172), PP 107-129.

[21] Margot I. Visser-Bochane, Sijmen A. Reijneveld, Wim P. Krijnen,Cees P. van der Schans, \& Margreet R. Luinge. (2020). Identifying Milestones in Language Development for Young Children Ages 1 to 6 Years. Academic Pediatrics, 20(3), PP 421-429.

[22] Patton, M. Q. (1990). Qualitative evaluation and research methods (2nd Ed.). USA: Sage Publications.

[23] Robert Savage, Kim Cornish, Tom Manly \& Chris Hollis. (2006). Cognitive processes in children's reading and attention: The role of working memory, divided attention, and response inhibition. British Journal of Psychology, 97(3). PP 365-385.

[24] Rong Xie (2021). The Effectiveness of Total Physical Response (TPR) on Teaching English to Young Learners. Journal of Language Teaching and Research, 12(2), PP293-303.

[25] Shirou Kunihira \& James J. Asher. (2009). The Strategy of the Total Physical Response: An application to Learning Japanese. IRAL - International Review of Applied Linguistics in Language Teaching, 1(4), PP277-290.

[26] William A. Corsaro. (1981). The development of social cognition in preschool children: implications for language learning. Topics in Language Disorders, 2(1), PP 77-77.

[27] Wang Li. (2008). Application of TPR Teaching Method in Children's English Teaching. Heilongjiang Institute of Education Newspaper, (1), 185-186.

[28] Yu Zhenyou. (1999). Asher Second Language Acquisition View and TPR Teaching Methods. Foreign language teaching, (2), 21-25.

[29] Zhong Jing. (2002). On the Cultivation of Interest in Foreign Language Learning by TPR method. Journal of Huizhou College (Social Science Edition), (2), 101-104.

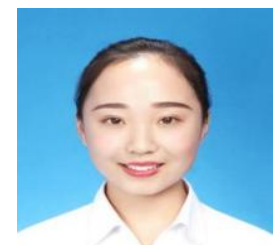

Yujing Duan was born in July 1995 in Zhoukou City, Henan Province, China. In July 2019, she graduated from Luoyang Institute of Technology, Luoyang City, Henan Province, majoring in preschool education and minoring in English. From September 2019 to July 2020, she worked as a teacher in Luoyang, Henan Province. In September 2020, she was admitted to Zhejiang Normal University in Jinhua City, Zhejiang Province. She is currently a graduate student in the School of Teacher Education, majoring in Teacher Education. Her research interests include teacher education, preschool education, and English teaching. 